\title{
EL CASTILLO NO EXISTE
}

\author{
THE CASTLE DOES NOT EXIST**
}

\section{Alí Víquez Jiménez*}

\section{RESUMEN}

Este ensayo se centra en el desarrollo de la idea, sugerida por Marthe Robert, de que en el universo ficcional kafkiano el castillo no existe más que como una creación verbal. Intenta desentrañar algunas de las consecuencias de tal en el ámbito de lo que esto significa para la condición humana que el personaje de K. representa. Además, plantea una lectura conclusiva de la obra de Kafka a partir de lo que implica la postergación en apariencia infinita del encuentro con la trascendencia.

Palabras clave: Literatura checa, narrativa europea, novela, Kafka, filosofía kafkiana.

\begin{abstract}
**
This essay aims in the idea suggested by Martle Robert, in which the kafkian's fictional universe The Castle (Das Scholss) only exists as a verbal creation. This document tries to figure out some of the consequences of it and what it means for K's (a character) human condition. Furthermore, it suggests a conclusive reading about Kafka's work from the implication of postponement in a finite appearance of the encounter with transcendence.
\end{abstract}

Key Words: Czech literature, European narration, novel, Kakfa, kafkian's philosophy. 
La noche malhadada en que K. llega a la aldea, la niebla y la oscuridad le impiden ver demasiado. Hay una espesa nieve que lo cubre todo, y todo lo confunde. No se percibe ningún castillo: "K. permaneció largo tiempo sobre el puente de madera que llevaba de la carretera general al pueblo, con los ojos levantados hacia aquellas alturas que parecían vacías.” (Kafka, 1981, p. $29^{1}$ ).

¿Parecen vacías o lo están? ¿Qué nos hace suponer que K. no acierta ahora, cuando (al menos, según lo que se nos revela) cree desnuda la colina donde luego se le hará saber se levanta el escurridizo castillo que se pone a perseguir? Después de todo, no será jamás el propio K. quien pueda dar fehaciente testimonio de que existe tal. Repasemos algunas informaciones.

En primer lugar, al principio K. parece ignorar que hay un castillo. Cuando se halla, esa primera noche, acomodado a la mala, en un jergón y en mitad de un salón donde todavía beben los campesinos, en un mesón de ínfima categoría, y se le despierta por parte de la autoridad (una ínfima también, pero autoridad al fin: el hijo de un subalcalde) para hacerle ver que necesita permiso del castillo para pernoctar en la aldea, ya que esta pertenece al primero, lo que manifiesta $\mathrm{K}$. es su desconocimiento al respecto, hasta ese momento: “¿En qué pueblo me he extraviado? ¿Existe, pues, un castillo aquí?" (Kafka, 1981:30). De manera que K. no ha tenido noticias previas de castillo alguno; su venida a la aldea ha sido motivada por una oscura contratación en la que aquel no ha mediado. Declara ser “...el agrimensor que el señor conde ha mandado llamar" (Kafka, 1981, p. 31), sin entrar en los detalles del llamado; se deduce que es, pues, de un conde de quien ha tenido nuevas y con quien ha establecido algún contacto --se adivina que, eso sí, muy indirecto-previo a su arribo. Cuando, casi de inmediato, asume $\mathrm{K}$. que hay un castillo, lo hace porque se le ha informado (no poco autoritariamente, aunque debe admitirse que K. no se deja intimidar con facilidad) de que así es, y -suponemos-porque no había de extrañarle al agrimensor que el conde habitase uno.
En segundo lugar, la vista del "castillo", disipadas la oscuridad y la niebla, al día siguiente, no es descrita sin ambigüedad. De lejos se lo admira sin problema ("Ahora veía el castillo que se destacaba limpiamente allá arriba en el aire luminoso..." (Kafka, 1981:37)), pero no dejan de sembrarse dudas en cuanto a su verdadera naturaleza ("No era ni un viejo castillo feudal ni un palacio de fecha reciente, sino una vasta construcción compuesta de algunos edificios de dos pisos y un gran número de casitas prensadas las unas contra las otras; si no se supiera que era un castillo, se habría podido creer que se trataba de una aldea." (Kafka, 1981: 38; el destacado es mío)). Más de cerca (mejor sería decir que menos de lejos, puesto que K. nunca se acercará de veras), se lo juzga todavía menos castillo: “...al aproximarse, se sintió defraudado; este castillo no era, después de todo, más que un villorrio miserable, un montón de casuchas pueblerinas que en nada sobresalían, de no ser, si se quería, por el hecho de que todas eran de piedra; pero el revestimiento de argamasa, ausente desde hacía mucho tiempo, y esa piedra parecían desmenuzarse. Un recuerdo fugitivo vino a golpear el espíritu de K.: pensó en su ciudad natal. Esta no era apenas inferior a este pretendido castillo..." (Kafka, 1981: 38; el destacado es mío).

En tercer lugar, cuando K. supone hallarse a la vera del camino que une el castillo con la aldea, se entera de que no se produce ningún tránsito por allí: “-Esta es (...) la carretera que conduce al castillo -objetó K. / --Poco importa -dijo el hombre con cierta crueldad--; por aquí no hay tránsito.” (Kafka, 1981: 48) ¿Cómo es posible que nadie se mueva desde la aldea al castillo o viceversa si se supone que todo en ese lugar gira en torno a la autoridad que el castillo ejerce sobre la aldea?

Propongo aceptar, entonces, la posibilidad de una lectura de El Castillo que parta del hecho de que tal castillo es una suposición no comprobada ${ }^{2}$. Admitamos que se habla (y mucho) de él; admitamos que todo parece girar a su alrededor, pero démosle al famoso castillo el estatus de ficción dentro de la ficción. Como Dulcinea del Toboso, el castillo ejerce 
su influencia en las vidas de los personajes sin que su existencia sea más que una quimera. (Recordemos que, cuando se cuenta con un grupo dispuesto a afirmar la realidad del yelmo de Mambrino por sobre la de una bacía de barbero, es el yelmo lo que resulta funcional.) Por lo demás, la inexistencia del castillo más que como una creencia generalizada que se traduce en una instancia que lo controla todo, no sería una novedad en Kafka: también en El Proceso llegamos a sospechar que no hay una autoridad judicial encargada realmente del juicio, lo que no obsta para que a Joseph K. lo decapiten; también los constructores en La muralla china atisban que no hay un emperador verdadero, lo que no les impide consumir sus vidas trabajando en el dilatadísimo proyecto imperial.

Esta propuesta nos permite acrecentar la paradoja, gesto por lo demás kafkiano. Pues habiendo un castillo, es posible pensar en ingresar en su interior, por muchos que sean los obstáculos, y, en el caso de K., salta a la vista que estos no son escasos ni de poca importancia. Aun así, habiendo un castillo, cualquiera puede entrar en él, al menos como posibilidad teórica. Ningún lugar que exista realmente puede estar por completo vedado para nadie: esta es una idea que, aunque no se exprese, parece razonable suponer en la mente de K., y vendría a justificar esa no por terca injustificada insistencia con que se conduce. La prohibición para entrar puede darse; los impedimentos quizá sean abundantes, ingentes, hasta exasperantes, como a menudo ocurre en el mundo kafkiano. (En un ensayo anterior, "Los procesos invisibles", insistí en la caracterización onírica que tienen las creaciones kafkianas. El suyo es, como muchos han hecho notar, un mundo de pesadillas, en el cual los absurdos - por ejemplo, querer entrar en un castillo fantástico-son perfectamente aceptables. En particular, en El Castillo, tenemos también algunos de los indicios pesadillescos más propios de Kafka: como en La metamorfosis y en El proceso, el personaje central despierta (o cree despertar) en las páginas iniciales y entonces se ve envuelto en una serie de líos anómalos. Otro indicio en quien menos corre atrapa a un venado.

Distinto es el panorama si el castillo ni siquiera existe. Entonces, y sólo entonces, es imposible ingresar en él. K. pierde el tiempo y se lo hace perder a quienes involucra en sus planes y maniobras. Pero habría que añadir que solamente un incipiente K., al principio de la obra, no da por un hecho la existencia del castillo. Aunque este ente no ofrece pruebas de existir, parece que nadie se atreve a dudar. Se me puede alegar que sí las da, pero yo argüiré que todas son refutables. Que los señores funcionarios del castillo se dejan ver fuera de él... Ese es precisamente el problema: fuera de él. Que la gente recibe órdenes y ejecuta proyectos que provienen de las instancias internas del castillo... Sólo sabemos que existen las órdenes y los proyectos, y se nos dice que vienen del castillo. Que algunos personajes afirman ingresar y hasta vivir en el castillo... Cualquiera puede aseverarlo, y el hecho es que también hay quien, como Barnabás, en momentos de franqueza con su familia, admite sus dudas sobre si ha estado realmente en el interior del castillo y sobre quiénes son aquellos con los cuales interactúa en esas visitas a un misterioso lugar: “¿Pertenece realmente al servicio condal lo que hace Barnabás?, nos preguntamos entonces. Cierto que entra en las oficinas; pero, ¿son éstas el verdadero castillo? (...) Barnabás habla con funcionarios, Barnabás recibe mensajes para transmitir, pero, ¿de qué funcionarios, de qué mensajes se trata? (...) Imagina: ¡estar al servicio de Klamm! ¡Hablarle cara a cara! ¿Pero es así? Sí, es así, ciertamente es así. Pero, ¿por qué Barnabás duda de que el funcionario al que se llama Klamm en esa oficina sea realmente Klamm?" (Kafka, 1981, pp. 266267) Finalmente, que todo parece organizarse en torno a las potestades del castillo... Sí, admito que eso es una impresión justificada, pero nada más que eso. ¿Quién nos puede asegurar que la aldea no funciona por sí misma, organizada, es cierto, en torno a una creencia en una instancia superior, una autoridad que se identifica con un hipotético castillo, pero sin que la existencia de este último sea verdadera? ¿Acaso las iglesias 
no tienen largos siglos de existir y de ejercer una autoridad que en ocasiones se ha juzgado incontestable? Redacto estas líneas en un país cuya Carta Magna incluye un bochornoso y trasnochado estatus confesional del Estado, en detrimento de todos aquellos que no somos católicos. ¿Y quién nos puede asegurar la existencia de ese dios que este grupo proclama?

Ahora bien, desde esta perspectiva, K. se hallaría completamente perdido. Pues varias son sus razones para intentar ingresar en el castillo. En primer lugar, es un asunto de voluntad. K. ha decidido que su destino está dentro del castillo. A diferencia del Joseph K. de El proceso, a quien la autoridad viene a buscar, $K$. es quien se presenta a la aldea, sin que nadie lo fuerce, con la clara misión de hacerse escuchar por el conde y de trabajar para él. Es cierto que dice que el conde lo ha mandado llamar, pero no hay indicio alguno de que K. haya debido aceptar, más que por soberanísima decisión, tal llamado.

Siempre, entonces, le sería posible cambiar de opinión. Ello es verdad, aunque no se halla exento de problemas. Pues si K. modificase su decisión inicial, no sería ahora el resultado de su libre voluntad, sino la imposición de los demás. Desde la noche de su llegada, una gran mayoría de quienes conoce, sean o se digan funcionarios o no del castillo, le hacen ver que no se le permite ingresar en este y se esmeran en ponerle obstáculos. Si K. determina que ya no quiere ir al castillo, simplemente está cediendo ante la voluntad de los demás.

No se trata de mero empecinamiento. Es que la voluntad de ir sólo puede ser equivalente a la voluntad de no ir cuando ambas opciones se ofrecen como realizables. Pero si alrededor de $\mathrm{K}$. prácticamente todos le repiten que debe desistir en su camino al castillo, entonces K. sólo puede posponer su decisión de no ir, si quisiera tomarla, para cuando no le estén apuntando con una pistola en la cabeza. El estado de amenaza en que se encuentra K., acorralado por las circunstancias, limita -al menos en buena parte-su libertad para decidir. (Sé bien que este razonamiento no es demasiado riguroso. Pues K. tiene dos opciones en su circunstancia concreta: continúa intentando llegar al castillo, pese a los obstáculos, o decide que no vale la pena seguirse desgastando ante estos y se va. He aquí una decisión que es libre, y no podemos posponer el ejercicio de la libertad únicamente porque las circunstancias sean adversas; de ser así, muy rara vez lograríamos tomar decisiones o cambiarlas. Pero mi intención no es mostrarme lógicamente riguroso, sino proceder de un modo kafkiano. Desde esta última -digamos-actitud, el razonamiento, creo, es como lo describo).

Un planteamiento algo distinto, pero que da los mismos resultados, trasluce en el siguiente aforismo kafkiano, que tampoco es muy riguroso pero sí muy interesante: "Un hombre posee voluntad volitiva $\mathrm{y}$, además, por triplicado: en primer lugar, era libre cuando quiso esta vida; ahora, sin embargo, ya no puede anular la decisión, pues ya no es el mismo que quiso con anterioridad; sería como si ejecutara su voluntad primigenia de vivir. / En segundo lugar, el hombre es libre porque puede escoger el camino y la forma de marchar por la vida. / En tercer lugar, es libre al poseer la voluntad, como aquel que será de nuevo una vez, de marchar por la vida en cualquier condición y de esta manera llegar hasta sí mismo, aunque por un camino que, si bien es elegible, es en todo caso tan laberíntico que no podrá dejar sin tocar el más pequeño fleco de esta vida. / Esta es la trinidad de la libertad volitiva, aunque también, ya que se produce simultáneamente, constituye una unidad, y constituye en el fondo tal unidad que no hay lugar para una voluntad, ni libre ni esclava." (Kafka, s.f., p. 7) De manera que al final la voluntad para alejarse del destino elegido es anulada, luego de elegir ese destino, según Kafka, si lo estoy siguiendo bien ${ }^{4}$. Otro aforismo así lo resume: "Si se llega a un punto determinado, ya no hay regreso posible. Hay que alcanzar ese punto." (Kafka, s.f., p. 8)

En segundo lugar, está el asunto del viaje. K. argumenta, en varias ocasiones, que ha emprendido un viaje extenso y costoso, y no desea por ello devolverse ahora, cuando se encuentra tan cerca de su destino, el dichoso castillo. Incluso ha dejado mujer e hijo en otra parte, lo que -por cierto-no le impide desarrollar planes matrimoniales con Frieda por 
considerar que esta unión puede ser útil para sus ambiciones. El viaje es, en cierta forma, el precio que $\mathrm{K}$. ha pagado previamente a su arribo a la aldea, para estar allí. Ha perdido a su familia (no parece albergar intenciones de establecerse y hacerla venir; de ser así, la relación con Frieda no habría tenido la dirección que tiene, hacia una formalización) y se ha alejado de su país. Recordemos que, para Kafka, el vínculo familiar es el más importante que un ser humano puede desarrollar, como lo demostraría su célebre (y en apariencia muy sincera, aunque esto es mero albur) Carta al padre; se trata de un altísimo precio. Por empinada que nos parezca la subida final al castillo, K. piensa que ya ha hecho una parte tan considerable del camino que no vale la pena rendirse ahora ${ }^{5}$.

Es frecuente, desde siempre, en la literatura, el tópico del viaje. Odiseo, don Quijote, Gulliver y tantos otros viajeros nos presentan propuestas que enfatizan en formas de ver las vicisitudes y dificultades de ese viaje que es la vida. En el texto kafkiano, en cambio, el énfasis está puesto en los problemas del arribo. No conocemos el viaje de K.; sólo sabemos que no ha resultado sencillo. Su vida, como la de todos, ha transcurrido cuesta arriba. Pero lo peor estaba por ocurrir: llegado a su destino, este le es negado.

Otro aforismo kafkiano reza: "Hay una meta, pero ningún camino. Lo que llamamos camino es duda." (Kafka, s.f., p. 2) Creo que en el caso de K. ocurre más bien al contrario: los caminos están, en la penumbra si se quiere, pero la meta no existe. El aforismo sostiene lo que K. desea pensar, justamente para no caer en la desesperación total. Aunque parezca muy extraño, K. - ese personaje metido en un laberinto que no puede ser más agobiantees un individuo cuya fe en la existencia del castillo, su meta, le asegura una esperanza. Debe continuar albergando esa fe para poder vivir como él desea, al menos en un hipotético futuro. $\mathrm{Si}$ se me permite, puedo agregarle al aforismo que "lo que llamamos meta es fe".

Por otro lado, no ha de pasarse por alto que la principal motivación de K. para entrar en el castillo es su deseo de ejercer su profesión de agrimensor. De hecho, el castillo le parece solamente un medio para conseguir tal, y en alguna ocasión manifiesta su indiferencia ante la posibilidad de vivir dentro de él o más bien en la aldea: hará lo que mejor convenga a su trabajo. En el ensayo inmediatamente anterior a este ("El fatal Kafka y las ventajas de la incomprensión") enfaticé en el hecho de que Kafka concebía su propia existencia radicalmente divorciada entre el empleo burocrático y enajenante que se veía forzado a ejercer y su dedicación a la literatura. No se goza de una vida satisfactoria si se realiza cualquier trabajo; hay que tener el que uno quiere. Además, la existencia se define por el empleo: ello es patente en la obra de Kafka, cuyos personajes se llaman no tanto por sus nombres como por sus ocupaciones. De aquí que K. no se conforme con ser el bedel de la escuela; aparte de las consideraciones económicas adversas (¡le dicen que más adelante considerarán si se merece un salario!), está el asunto vocacional. El agrimensor no puede claudicar en este aspecto; negarse como agrimensor equivale a una pérdida de identidad irreparable. No en balde, la propuesta para que $\mathrm{K}$ se convierta en bedel de la escuela proviene del alcalde, quien es aquel que se encuentra más decidido a provocar el retorno de K. a su país de origen.

K. sólo puede ser agrimensor para seguir siendo él. Si K. deja de ser agrimensor, para transformarse en bedel, también deja de ser K. Y su empleo como agrimensor sólo se puede consolidar si K. consigue ingresar en el castillo: está claro que la medición de terrenos implica una dirección al respecto que únicamente vendría de una instancia de autoridad; vale decir que la agrimensura no se puede ejercer como una profesión independiente, puesto que la validez de este quehacer procede de la orientación y del reconocimiento superiores. La palabra del alcalde, al asegurar que en la aldea no se necesita ejecutar ninguna labor de agrimensura, es lo más urgente que debe refutar K. (Bueno, en realidad K. también debería esmerarse en refutar la tesis de la inexistencia del castillo que defiende este ensayo: si no lo hace, es porque nadie se la presenta en el texto, pero está claro que sin castillo no hay lugar para un agrimensor 
en la aldea. Esta es en el fondo la dimensión trágica que le veo al personaje: solamente puede conservar su identidad en un mundo que es en rigor inexistente; está, por lo tanto, condenado a perderse como individuo en el momento en que descubriese y aceptase la verdad. Volveré sobre esta, que es la dimensión trágica del personaje no como individuo sino como representante de la condición humana.)

Me permito aquí un desvío (pertinente, espero) hacia otro texto kafkiano. Véase lo que sucede en el mundo de Gregorio Samsa, debido - precisamente - a que este personaje acepta su perpetuación en un empleo que no le es querido. No sólo termina convertido en un monstruo, sino que esta transformación implica, en primer lugar, su pérdida del tan odiado trabajo, con las consiguientes desventajas económicas para él y su familia. Llama la atención el que Gregorio Samsa, al despertar tras agitado sueño y verse convertido en insecto, dirige sus pensamientos, a toda prisa, hacia la aridez y la fatiga propias de su trabajo como viajante de comercio: “--¡Ay, Dios! -díjose entonces--. ¡Qué cansada es la profesión que he elegido! Un día sí y otro también de viaje. La preocupación de los negocios es mucho mayor cuando se trabaja fuera que cuando se trabaja en el mismo almacén, y no hablemos de esta plaga de los viajes: cuidarse de los enlaces de los trenes; la comida pésima, irregular; relaciones que cambian de continuo, que no duran nunca, que no llegan nunca a ser verdaderamente cordiales, y en las que el corazón nunca puede tener parte. ¡Al diablo con todo!” (Kafka, 1970: 146 ${ }^{6}$ )

Es sorprendente que en un momento tan inusual como el que Gregorio Samsa está viviendo, el personaje tenga espacio para una reflexión sobre su empleo. No todos los días se convierte uno en un insecto, como para que una cosa así no desvíe la atención de los temas cotidianos. A menos, claro, que sea precisamente porque esos enojosos temas cotidianos, esa inconformidad con las condiciones del empleo, son los que provocan el que el personaje se sienta transformado en insecto. Gregorio Samsa es incapaz, por responsabilidad hacia una familia que le toca sostener, a pesar de que él es el hijo y no el padre, de abandonar su odiado trabajo; podríamos decir entonces que en cierta manera no le queda más remedio que convertirse en insecto para librarse del yugo laboral. Así, su metamorfosis es el efecto de su permanencia en un trabajo enajenante, que requiere de él una movilidad enemiga de la consolidación de los afectos, y esto lo hace ser un monstruo: el trabajo, por sus viajes continuos, lo separa de los demás seres humanos. La paradoja estriba en que, una vez transformado, la metamorfosis se convierte en causa de despido: su empleo lo ha tomado, lo ha hecho un monstruo, y después lo desecha por ser precisamente esa cosa horrible en que lo ha convertido. Luego vendrá también el rechazo por parte de sus padres y de su hermana, de quienes también se ha separado afectivamente por causa de sus viajes, aunque tal vez en menor grado, lo que no obsta para que al final el resultado sea el mismo rechazo. Gregorio Samsa se libra, sí, de ese empleo, pero es demasiado tarde porque ya ha dejado de ser un humano.

Dos aspectos de este pavoroso cambio de estado deseo destacar. En primer lugar, el hecho de que la metamorfosis de Gregorio implica la reinserción en el empleo del resto de su familia, con resultados para estos últimos más bien halagüeños. El padre recupera un vigor perdido; la madre también mejora; la hermana incluso florece, llena de vida. La pintura final de la familia que se ha librado del monstruo Gregorio, nos dice: "Y cuando, al llegar al término del viaje, la hija se levantó la primera y estiró sus formas juveniles, pareció cual si confirmase con ello los nuevos sueños y las sanas intenciones de sus padres." (Kafka, 1970: 78) Es que, a diferencia de Gregorio, ellos han viajado (así se puede leer la alusión al paseo en tranvía cuya conclusión coincide con la del texto) adonde han querido.

En segundo lugar, y así retomo El Castillo, los continuos viajes de Gregorio se presentan enajenantes, como ya se ha comentado: esto puede servirnos para entender por qué K. se niega en redondo a seguir viajando, incluso cuando Frieda se lo sugiere como una posibilidad alentadora. El que continúa dando vueltas sin fin se abisma en su propia perdición. Por eso 
K. sabe que ha llegado y no puede continuar en los caminos; no consentirá en convertirse en un monstruo. El viaje sin meta (caso, a fin de cuentas, del viajante de comercio Gregorio Samsa) es la peor elección que puede hacerse.

Pero ingresemos ya, si no en el castillo, en la dimensión connotativa de este, aspecto que he venido eludiendo -al menos parcialmentehasta este punto del ensayo. Es un hecho, desde Barthes y $S / Z$ con seguridad, que leer literatura es leer connotativamente. Allí decía Barthes que el texto clásico o legible se ha elaborado siempre con arreglo a un primer sentido, denotado, que luego se carga de segundos sentidos, los connotados. Un hipotético texto escribible, más allá de este planteamiento, permanece hoy, más de cuarenta años después de $S / Z$, como una mera elucubración barthesiana que sigue sin mostrar ejemplos concretos; o, si los hay, deberá admitirse que son, efectivamente, ilegibles, por cuanto no existen más de tres lectores capaces de someterse a la tortura de experimentos tales. Mejor es abstenerse de citar ejemplos, por razones obvias.

Ahora bien, en el concreto caso kafkiano, una discusión en torno a la connotación parece caracterizar parte del panorama actual. Primero, por bastante tiempo, abundaron los que proponían una clave de lectura connotativa $\mathrm{y}$, sobre esta base, desarrollaron una lectura más o menos sostenible. Debería admitirse que, con la aparentemente más sana de las intenciones, aunque no sin cargar bastante la mano hacia sus particulares intereses ideológicos, inicia esta línea de lectura el propio Max Brod, quien interpreta en clave de obra religiosa, dentro del judaísmo en que parece haberse interesado Kafka. En particular, sobre El Castillo, Brod pretende que K. busca la gracia divina, mediante la integración -infructuosa-en una comunidad $^{7}$. Distintas claves connotativas han sido sugeridas desde entonces (unas más interesantes que otras; no me negaré a revisar un par de ellas muy pronto). En un segundo momento, otro sector de la crítica parece haberse cansado de buscar y proponer claves, y más bien sostiene que Kafka no debería ser interpretado connotativamente. R. M. Albérès y Pierre de Boisdeffre (en Isaacson, 2005, pp. 84-86) pueden servirnos como representantes de esta suerte de abstencionismo connotativo para el caso kafkiano, cuando (sobre El proceso y El castillo) sostienen que “...no se podrá explicar esos textos, que no son la alegoría de una doctrina, sino la alegoría de un enigma... Son muy esotéricos, en el sentido de que comentarlos para encontrar en ellos una explicación será siempre pueril: están construidos para suscitar sucesivamente todas las interpretaciones y cada una de ellas -así como su suma-resulta insuficiente... En cuanto a la interpretación privilegiada y definitiva, no existe en lo absoluto, por la simple razón de que Kafka no la conocía y precisamente sólo escribía textos para explicar que era inhallable." Concuerdo con Isaacson cuando juzga más interesante que pretender una suerte de "...circuito cerrado según el cual (Kafka) escribe para demostrar que la interpretación definitiva de lo escrito es imposible..." (Isaacson, 2005: 85), la opinión de los autores citados de que "...las grandes alegorías kafkianas no son interpretaciones de la existencia; son imágenes de la existencia. No se puede decir que el sentido de la vida no tenga solución, es necesario decir con mayor exactitud que nunca ha podido ser formulado con precisión, lo que es peor. Hay ecuaciones insolubles; pero también casos en que incluso la ecuación no se puede plantear... El error de los filósofos es pretender dar la ecuación que podría permitir buscar el sentido de la vida; después de lo cual, si no están demasiado encerrados en sí mismos, reconocen que esta ecuación no tiene soluciones. Después de Kierkegaard y de los místicos negativos, Kafka agrega algo a la filosofía, la corrige: no muestra que el problema sea insoluble; sólo muestra que el problema no puede ser mostrado de manera clara... Y ahí está, sin duda, el verdadero tema de El proceso y El castillo." (Albérès y Boisdeffre, en Isaacson 2005: 85).

La verdad es que, por mucho que nos parezca siempre que cualquier connotación concreta es insuficiente ante $\mathrm{El}_{\text {castillo }}{ }^{8}$, es imposible dejar de operar connotativamente, dado que ello equivaldría a negarse a cooperar 
con lo que, en rigor, parece más consustancial a la obra kafkiana: su necesidad de ser interpretada9. Sólo queda añadir (es José Isaacson el primero en notarlo) que Albérès y Boisdeffre tampoco se abstienen de operar connotativamente en su aproximación al texto kafkiano: decir que Kafka desconoce un sentido último de la existencia es también proponer una clave de lectura connotativa para El castillo.

Voy a repasar brevemente dos posibilidades connotativas acerca de El castillo sugeridas por la crítica. No pretendo elaborar lo que resultaría un muy incompleto estado de la cuestión, sino que selecciono aquellas propuestas que me interesa modificar de una manera que juzgo válida al agregarles mi hipótesis de lectura en cuanto a la inexistencia del castillo. Es decir, selecciono las propuestas que soportan el leerse desde mi punto de vista, y veo qué es lo que producen entonces. La primera es una tendencia de lectura de la cual hay sobrados exponentes; la segunda se debe a Marthe Robert.

Tenemos, para comenzar, la lectura sociologizante de Kafka, posiblemente la más difundida, si tomamos en cuenta que el adjetivo "kafkiano" ha llegado a ser incorporado al léxico de uso común para calificar aquellas instancias burocráticas cuya complejidad es indescifrable, cuyos poderes son temibles y cuya capacidad de entrabamiento da la impresión de no tener fin ${ }^{10}$. A sólo dos décadas de la muerte de Kafka, Auden ${ }^{11}$ lo consideraba "...el autor que más se acercó a tener con nuestra época la relación que con la suya tuvieron Dante, Shakespeare o Goethe..."; esto por cuanto Kafka es el autor que mejor le toma el pulso al momento histórico en el que los sistemas políticos y económicos (no se piense sólo en el nazismo y el estalinismo, también en el capitalismo actualmente triunfal) convierten al ser humano en un elemento enajenado de su propia vida, que ahora le pertenece a una organización incomprensible e impenetrable. Kafka retrata la cosificación a que nos vemos sometidos quienes vivimos en sociedades que nos representan (o, todavía peor, nos sustituyen) con números ciegos ante nuestras necesidades y deseos personales. Ingresar en el castillo significaría para K. el llegar a tener éxito en el aseguramiento de su propio lugar en esa sociedad: con mucha suerte sabría K. cómo funciona la autoridad o, lo más probable, al menos, lograría de esta el reconocimiento de su identidad personal como el agrimensor y la dignificación de su trabajo. Decir que no existe el castillo equivale entonces a denegar la posibilidad de tal mejoramiento, que, aunque remoto, ocurre mientras haya un castillo. Pero ninguno de nosotros puede aspirar a un reconocimiento de nuestra individualidad en un sistema que no posee un centro neurálgico desde el cual sea posible realizar tal reconocimiento. En este sentido, juzgo necesario diferenciar posibilidades de sistemas políticos. Pues el nazismo y el estalinismo, justamente, sí parecen haber contado con centros neurálgicos bien ubicados: de aquí que resultara posible penetrar en ellos (sus castillos) y finalmente destruirlos. En estos casos, admitamos que sí existieron los castillos, y por costoso que fuese (y, sobre todo, trágico) resultó factible el ingreso. Pero ¿qué hay del sistema globalizador capitalista actual? ¿Dónde tiene su castillo? En su esclarecedor libro El verdadero rostro de la globalización (2008), Luis Paulino Vargas nos hace ver un panorama de la actualidad socioeconómica tan aterrador como kafkiano en este sentido: los centros de poder del mundo globalizado ciertamente existen (y Vargas los puntualiza), pero su imbricación es tan compleja y es tan evidente la ausencia de un único centro neurálgico de toma de decisiones que, en la práctica de nuestra sociedad, el castillo no existe. Nos enfrentamos a un monstruo de mil cabezas cuya fuerza estriba precisamente en que no tiene una sola que pudiera arrancársele. La intuición kafkiana de tal va mucho más allá entonces de los pavorosos episodios del nazismo (en los que murieron sus hermanas, alguna de sus novias, y hubiera muerto él mismo de no ser por la -al fin de cuentas-piadosa tuberculosis que lo mató antes) y del estalinismo, y se extiende a nuestros días. Se me puede argüir aquí que, aunque disperso y complejo, sí hay un castillo: los actores hegemónicos y sus organizaciones pueden estudiarse y describirse, como lo hace Luis Paulino Vargas, pero yo argumentaré que 
la dispersión y la complejidad son tales que eso (tal como intuye K. en la primera vista) ha dejado de ser un castillo, si alguna vez lo fue. Se trata de otra cosa, algo horrible cuya existencia ubicua no puede concebirse con el simple nombre de castillo $^{12}$.

La otra lectura que me interesa retomar es la que ve en la obra kafkiana una reflexión sobre las relaciones que el lenguaje instaura en las sociedades humanas. Esta lectura se puede adscribir fundamentalmente a Marthe Robert y está expuesta en un libro ya clásico dentro del aparato crítico que nos compete (Robert, 1969). Dice la crítica: "La mayoría de los exégetas, sorprendidos por la analogía entre el castillo inaccesible de Kafka y el del Graal o el de otros autores místicos, dan por sentado que la intención de Kafka era escribir una versión moderna de la leyenda, y así justifican su procedimiento descifrador. Ahora bien, esta era precisamente su intención, pero en su versión personal la búsqueda no tiene por objeto real al propio castillo, sino la crítica activa de los símbolos, metáforas, imágenes que acreditan en el espíritu de su héroe, así como a los ojos del lector y del crítico, la idea misma de que existe un castillo (...) Aguijoneado por una necesidad que no le concede el menor respiro, el héroe de Kafka se lanza a sí mismo y al mundo en un desafío sin precedentes, cuyo radicalismo sobrepasa casi los límites de lo humano. En apariencia, sin duda, lo que busca no tiene nada de inquietante: quiere establecerse en un pueblo humano cualquiera, y allí, casarse y vivir ejerciendo dignamente su oficio. Pero todo esto, lo tuvo que intentar conseguir en una sociedad en la que las relaciones del lenguaje, decisivas para la existencia de cada uno, están desnaturalizadas, falsificadas, vaciadas por un uso ignorante y perezoso, de modo que si rechaza la mentira oficial -y la rechaza--, no tiene más remedio que deshacer pacientemente el trabajo secular de las palabras para aprender, en fin, a pensar solo." (Robert, 1969: 101) No me duele reconocer entonces que Marthe Robert ha transitado antes que yo por la tesis fundamental de este ensayo, como se desprende del destacado en la cita anterior; mi propósito se puede ver como el de querer enfatizar entonces en las consecuencias en la lectura connotativa de lo trascendente del hecho de que el castillo es solo una creación lingüística. Mientras Robert enfatiza en la descripción de las operaciones lingüísticas en una sociedad regida por un castillo que es también una creación lingüística y es sumamente enajenante, yo subrayaré la dimensión metafísica implicada en una creación puramente verbal de un castillo. La lectura de Robert no solamente soporta la idea de que el castillo no existe; hay que decir con propiedad que la sugiere abiertamente, si bien desarrolla su planteamiento en una dirección más bien sociolingüística que metafísica, como la que yo quiero seguir con prioridad a partir de este momento. Leo, pues, el castillo como el espacio connotativo de lo trascendente en un sentido metafísico: es decir, más precisamente, el castillo como el símbolo de la existencia de la ley y de un Dios todopoderoso que la emana.

A menudo, personajes junto a $\mathrm{K}$. quieren hacerle notar que él entiende poco en relación con lo que pasa en su entorno. Es el caso frecuente de la mesonera, o de la misma Olga cuando explica a K. la desgracia familiar, para poner un ejemplo concreto que nos será de mucha utilidad (véase Kafka 1981: 299 ss). K. viene a ser juzgado como una especie de ignorante pertinaz, que no sólo debe su desconocimiento a su novatada, sino también a su terquedad para no aprender. Pero siguiendo todavía a Robert, podemos leer tal conducta no tanto como una muestra de estulticia sino de rebeldía. K. se rehúsa a dejarse dominar por las relaciones de lenguaje que provienen de la autoridad impuesta por el castillo, y acusa de mentirosos esos usos lingüísticos. De hecho, buena parte de las acciones de K. tienen como fin el "reinterpretar": volviendo al ejemplo concreto que acaba de proponerse, mientras que Olga se juzga perdida, tanto ella como su familia, por decisión del castillo, K. sostiene lo contrario: "--¿Y dónde ves la influencia del castillo? -preguntó K.--. Hasta el momento, no parece haber entrado en juego todavía. Todo cuanto me has contado hasta aquí puede explicarse por una inquietud irracional de las gentes, por el placer que les 
causa la desgracia ajena y por la infidelidad de los amigos - cosas que pueden hallarse en todas partes--. Y, referente a tu padre --eso al menos es lo que me parece--, por una cierta estrechez de espíritu, pues, ¿qué era ese diploma en el fondo? El certificado de su capacidad; pero ¿no la conservaba en el fondo? Y si esa capacidad le hacía indispensable, tanto mejor; habría hecho la tarea realmente difícil al capitán tirándole el diploma a los pies a partir de la primera palabra." (Kafka, 1981, p. 306) Este caso es especialmente importante porque demuestra cómo K. se aleja de las lecturas que sobre el castillo se le presentan (las cuales, invariablemente, lo dan a él por caso perdido) como un camino no para no entender sino para no darse por vencido, como lo hizo el padre de Olga cuando cayó en desgracia a los ojos de las autoridades. Al hablar de este individuo, K. también habla de sí mismo: su habilidad (como agrimensor) no será puesta en entredicho, ya que, a diferencia del padre de Olga, no es el suyo un espíritu estrecho. Con esto, se nos indica (creo) que K. tiene mayores posibilidades de lectura de lo que ocurre a su alrededor, y por eso no se limita a darse por perdido sin más: sabe que la posibilidad de continuar luchando depende directamente de la de interpretar la realidad de manera diversa.

Esto hace de K., en primer lugar, un rebelde. Su rebelión reviste la forma de una lectura alternativa de los datos que recaba sobre el castillo, datos que invariablemente le vienen manoseados: recuérdese que $\mathrm{K}$. logra, como mucho, el recibir ambiguas notas de Klamm, la supuesta autoridad del castillo más alta de la que llega a tener noticia, y nunca concreta la entrevista con él que tanto desea. Ahora bien, no se trata de que K. cometa alegremente cualquier tipo de lectura, como quien lee un libro dándose libertad interpretativa irrestricta, como lo haría algún lector bisoño y demasiado fantasioso. Al contrario, trata $\mathrm{K}$. de ser riguroso en mayor grado que quienes le rodean. Cabe recordar aquí la distinción de Eco (1981) entre lecturas ilegitimables y lecturas legitimables: una lectura sólo puede aspirar a esta segunda condición cuando expone y justifica las bases sobre las cuales se construye. Es esto en lo que invierte gran cantidad de su tiempo K.: en los intentos por legitimar ante los otros las lecturas divergentes (y, según él, más acertadas) que propone. La suya es una rebeldía interpretativa sumamente deseosa de legitimarse, que no escatima argumentos ni explicaciones. Dado el alto grado de manipulación previa con que recibe informaciones, debe $\mathrm{K}$. además invertir mucho tiempo en esclarecer el mensaje. Diríamos, pues, que el "ruido" en la lectura es tremendo: el texto le llega manoseado (como habiéndolo pasado por varios malos traductores) y masticado para su interpretación en un sentido adverso a sus aspiraciones; K. no tira la toalla y se dedica a reconstruir un original perdido y a interpretarlo de una manera favorable a él. Es un héroe, en primer lugar, de la lectura.

Ahora bien, ¿qué pasaría si K. se diera cuenta de que esos textos que lee con tanto esfuerzo de su parte sólo esconden una verdad: que no existe un castillo en el cual se producen originalmente? En lugar de emanar el lenguaje de un ser todopoderoso que lo genera para comunicar su voluntad (claro que con muchas dificultades, sobra decir que K. se da cuenta de estas), ese lenguaje es la mampara detrás de la cual se oculta el hecho de que no hay ningún ser todopoderoso. En lugar de un Dios (digámoslo sin tapujos) tartamudeante y contradictorio, incoherente y arbitrario, ningún Dios, sólo lenguaje atribuido a este. Eso explicaría mejor que cualquier pirueta teológica por qué el lenguaje atribuido al dios resulta tan confuso: como no hay tal hablante, quienes lo inventan y le ponen el verbo en la fantástica boca no pueden sino incurrir en las confusiones propias de una legión de impostores, un puñado de burdos falsificadores que se hacen pasar por muñecos de un inexistente ventrílocuo divino. Pero si K. llegase a conocer esto, y admitamos que es el único personaje en quien se asoma la suficiente independencia de criterio como para lograr pensarlo, estaría entonces definitivamente perdido, sus esperanzas de ingreso totalmente acabadas. Por eso parece que en Kafka todo se vale en relación con interpretar y reinterpretar un mundo confuso en el que Dios se oculta, excepto el atisbar que Dios no se oculta, simplemente no 
está. Llegar a este último punto equivale a dejar de leer el mundo como un manuscrito firmado por Dios (lo cual implica, en el mejor de los casos, descifrable) para abismarse en un mundo que no es más un texto coherente, sino una maraña de textos y, para peores, inauténticos, aunque, no por esto último, menos activos en su control de la realidad. La aldea sin castillo no es más que un caos que jamás se podrá descifrar: por mucho que el castillo estuviese lejano y bizarro, su existencia auguraba un sentido final, al cual se podría acceder: debe haber un conde y en él se resumiría la autoridad final. (Digo esto provisionalmente: digamos que un castillo donde habite un conde ofrecía esto como posibilidad teórica. Enseguida me corregiré tomando en cuenta las evidencias que la experiencia de K. nos ofrece.) No habiendo castillo, la aldea carece de sentido. La pesadilla kafkiana acabaría aquí, es cierto, pero acaso de la peor forma; quizás por ello el sueño se prolonga sin llegar a este punto ${ }^{13}$.

¿Nos enfrentamos, pues, en Kafka, con un autor incapaz de superar una especie de tremendismo ateo, que prefiere permanecer en una pesadilla de persecución de Dios antes de aceptar su inexistencia? Yo creo más bien que Kafka, quien nunca finalizó sus libros, lo hizo porque no deseaba inducir al lector a una conclusión como esta. Y la razón no ha de ser el preservar al lector de un estado deplorable, sino más bien el afán por preservar en el lector la libertad para dar, por sí mismo, ese paso. No se trata de que K. descubra la verdad de su condición en un mundo sin Dios y los demás nos demos cuenta gracias a él; se trata de que cada cual decida hasta cuándo quiere transitar en un mundo concebido como la creación de un Dios inexpugnable, y haga lo propio por terminar con la pesadilla, si esta fuere su elección, elección que no podemos atribuir al autor, acaso un hombre demasiado enamorado de sus miedos.

$\mathrm{Y}$ es que, además, si llegase a existir un castillo --supongámoslo por un momento--, este, al menos en lo que las andanzas de K. nos permiten vislumbrar, no tiene una organización coherente y descifrable. De ser así, no emanaría de él una aldea como la que conocemos: absolutamente ininteligible. Se atisba en el supuesto castillo un caos reinante. ¿Acaso es una bella perspectiva, la de una trascendencia en donde Dios es un ser tan confuso que su presencia no resuelve nada, más bien, al contrario, enturbia? Si lo que se sospecha que ocurre en el interior del castillo es tan caótico como lo que el exterior nos permite deducir, por aquello de que por la víspera se saca el día, entonces K. estará definitivamente amolado. Ya Wittgenstein nos hacía ver que, a los muy hipotéticos ojos de unos bienaventurados que mirasen en el cielo la presencia divina, nada les probaría que no se trata de una impostura ${ }^{14}$. Asimismo, aquel que lograse trascender hacia el castillo sólo parece destinado a encontrarse con más de lo mismo que ha hallado en la aldea: confusión y caos. La pesadilla que despierta a la trascendencia se encuentra dentro de otra pesadilla. No hay en Kafka (judío, al fin, por su crianza) asomo de ese optimismo cristiano que, pese a las enormes cuotas de sufrimiento, incomprensión y maldad del mundo real, logra explicarse todo ello como resultado de un plan divino rebosante de amor: Kafka dice más bien que, si la aldea es una completa desgracia, el castillo (su supuesto origen trascendente) las tiene todas consigo para ser todavía peor. Si este mundo es un valle de lágrimas, no hay ninguna razón para suponer que el otro, en el caso de existir, habría de ser mejor: la idea de que se sufre ahora para tener ganado el derecho de disfrutar después le parece a Kafka completamente injustificada y arbitraria. ¿Por qué no habríamos de sufrir sólo para prepararnos para seguir haciéndolo? Después de todo, este mundo a menudo se nos puede antojar una verdadera antesala del infierno ${ }^{15}$.

He adelantado que aquí se encuentra una dimensión trágica del personaje de $\mathrm{K}$. que nos retrata al ser humano en general. Abandonado por Dios (que no es señor de un castillo), K. no conseguirá jamás consolidarse como agrimensor, es decir, perderá su identidad. $\mathrm{Y}$ es que la identidad que vale para nosotros es la que se preserva de la muerte: por eso es válida la figura de un agrimensor, que depende para consolidarse como tal de la intervención de un castillo, para representar a los seres humanos. Estos sólo pueden querer ser algo más que futuro polvo 
en el viento, y sienten su identidad puesta muy en entredicho si no se le concede a esta boleto para ingresar en la eternidad. Ante una muerte concebida en ausencia de Dios, cobra inapelable validez la sentencia de que no somos nada.

Pero, por otra parte (nueva paradoja), la obra kafkiana, con todo y lo tremebunda la podemos vislumbrar, no deja de ser un llamado a la ruptura con la idea de que la pérdida (de la identidad, de la verdad divina, de Dios) es irreparable. Trágica, de acuerdo, pero recordemos que un desenlace funesto no está necesariamente implicado en la concepción de tragedia, aunque sí muy generalizado. Es decir, Kafka no esconde que el golpe de saberse desamparado en una aldea sin castillo es duro, tremendo, pero ¿por qué no asumir en el ser humano la capacidad para asimilarlo? Después de todo, la obra kafkiana parece también una invitación a despertar de la pesadilla, que te dice: "Si pensar que Dios no existe y aceptar que estamos solos y condenados a la muerte es terrible, no poco terrible es también el vivir pensando que sí existe, sólo que es inexpugnable, y que seguramente seguiría siéndolo incluso cuando lo conociéramos luego de nuestra vida terrenal". ¿Por qué no asumir en Kafka, entonces, algo que estoy seguro de que los lectores kafkianos quieren hacer a cada instante? Despertar de la pesadilla, aceptar que K. y los demás se imaginan un castillo inexistente, dejar de perseguir lo imposible de alcanzar, decir "ya basta de tanta patraña". Si eso nos lleva a un mundo en el que ya no podremos ser quienes éramos, un mundo en donde la agrimensura tan deseada es imposible, ello no deja de ser una opción al menos no peor que la que Kafka nos ha pintado con lujo de detalles en sus obras, en el destino intolerable de K. y de tantos otros de sus personajes. Sólo cambiamos de algo insufrible por algo similar, en el peor de los casos. Lo que quiero decir es que K. ya vive en un mundo horrible: ¿no sería mejor para él tratar de recomenzar su vida en un lugar que, a lo mucho, sería igual de malo que el anterior? Si Kafka quisiera justificar la búsqueda de la gracia divina, como lo pretende Brod, ¿por qué esbozaría una realidad en la que tal búsqueda sólo podría haber sido inspirada por un sádico temible? Imaginemos a un conde a cargo del castillo, con entero control sobre este: díganme si no habría que calificar de inaceptables sus planes y procedimientos ${ }^{16}$. En cambio, si pretende hacernos ver que continuar buscando a Dios es sencillamente un despropósito, por mucho que lo necesitemos, la historia de K. se halla perfectamente planteada ${ }^{17}$. Ir tras Dios es inevitable, es fundamental, y nadie se halla exento de sufrir ese destino, incluso como motivación de su existencia y resguardo para su propia identidad, pero es una pesadilla porque la meta no existe. Despertar es doloroso, pero está -me atrevo a insistir en ello-constantemente sugerido por la propia obra kafkiana, que no cesa de decir, sin decirlo jamás, que hay que poner un remedio a la situación de K. ¿Quién que lea no lo siente así ${ }^{18}$ ?

La avidez por entrar en el castillo no es, sin embargo, entre los personajes de esta novela, algo generalizado. La gran mayoría sólo prefieren que los dejen en paz; aceptan el rol que la autoridad condal les impone sin rastro de rebeldía, por chocante o miserable que resulte (caso de la familia de Barnabás, por ejemplo). Por un lado, se consideran incapaces de forzar algún cambio, por mínimo que sea; por otra parte, temen las consecuencias de abandonar el rol asignado, lo que podría interpretarse (y lo es, ciertamente) como un acto de rebeldía. Así que para los más, que juzgan a K. loco o tonto por moverse en otra dirección, no interesa penetrar en el castillo. Ello en primer lugar los trasladaría a territorios desconocidos y posiblemente peligrosos. Ninguna razón para abandonar la seguridad del estado actual; este podría ser adverso, pero sabe uno a qué atenerse.

Resulta entonces que la mayoría se declara creyente en el castillo, incluso muy atemorizada ante él, pero su fe no es un motor activo, sino un estado inercial. Estos pueden vivir un sueño de medianías, en donde no hay pasión ni siquiera por despertar. La relación con la trascendencia que nos pinta Kafka, en el nivel más generalizado de la sociedad, es de un temeroso desinterés. Obediencia a ciegas, con tal de evitar el conflicto y el riesgo. Indiferencia completa, con tal de no preocuparse más allá de 
lo estrictamente necesario ante el más allá de la aldea. La comunidad de la aldea vive lo que en rigor no deja de ser una tremenda contradicción, pues organiza su vida en torno a un castillo al cual teme sin interesarse verdaderamente en él. La gente cree en una trascendencia cuya verdad le aseguran y vive sometida a la autoridad que se impone en nombre de esa trascendencia, pero desvía la mirada cuando se trata de investigar sobre ella. La gente, en su inmensa mayoría, se limita a un estado de servilismo trascendente: sea por temor a la amenaza que se ciñe sobre su condición, amenaza que no cuesta ver, desde este punto de vista, como la de la presencia de la muerte y del sufrimiento ${ }^{19}$, sea por la mera costumbre de vivir así.

Habría otra posibilidad para explicarse la aceptación de una autoridad emanada de una trascendencia imaginaria, que me parece se explica muy bien en el caso de la familia de Barnabás. Se trata de la culpa. Por boca de Olga, su hermana, nos enteramos de la situación en que se han visto involucrados. La otra hermana, Amalia, despertó en un tal Sortini, un oscuro señor del castillo, un interés nada saludable; ella reaccionó con indignación ante ello, y he aquí que toda la familia cae en desgracia (comenzando por el padre, a quien no le iba nada mal como bombero) y, encima, se les hace cargar con la culpa por lo sucedido. La patanería de Sortini no tiene límites; tras ver a la muchacha en una fiesta le envía una carta de la que Olga dice: "No puedo repetirte el contenido. Sortini ordenaba a Amalia que fuese inmediatamente al hotel de los señores, por lo que debía partir antes de media hora. La carta estaba escrita en los términos más groseros que jamás había oído, y tuve que adivinar el sentido según el conjunto ${ }^{20}$. Para quien no conociese a Amalia y no hubiera leído más que una carta, la joven a la que había tenido el atrevimiento de dirigirse debía pasar por deshonrada, por honesta que fuese. No se trataba de una carta de amor, pues no contenía ninguna palabra tierna. Sortini parecía más bien irritado al ver que el aspecto de Amalia le había turbado y distraído de sus asuntos..." (Kafka, 1981: 289-290) K., por supuesto, se indigna: “--¡Esos son los funcionarios! -dijo K. al cabo de un instante--. ¡Esa es la ralea que hay entre ellos!" (Kafka, 1981: 290) Pero, además, añade que no comprende por qué Amalia iba a estar ya deshonrada por la carta, como supone Olga: “Cómo Sortini habría comprometido para siempre a Amalia con una carta semejante? Puede creerse por la forma como cuentas la historia, pero precisamente no es posible, era fácil darle todas las satisfacciones a Amalia y en algunos días el incidente habría sido olvidado. No es a Amalia, es a sí mismo a quien Sortini ha comprometido." (Kafka, 1981: 291; el destacado es mío) Se marca así en un caso concreto una constante en el contraste entre K. y los demás (con excepción, quizá en algunos momentos, de Frieda ${ }^{21}$ ): estos están dispuestos a razonar como sus victimarios asumiendo culpas que no les caben, mientras que $\mathrm{K}$. pega el grito en el cielo al ver tales despropósitos. La culpa es la gran arma ideológica mediante la cual se induce a la aceptación de una autoridad trascendente imaginaria. Pero K., quien tiene la capacidad de ver más claramente, no cae en el engaño ${ }^{22}$. Creo que, lejos de justificar la aceptación de la culpa, Kafka no hace sino denunciar su falsedad. No se le ha hecho suficiente justicia al autor en este sentido: abundan los que creen que Kafka toma sobre sus personajes las culpas: ¿debemos este equívoco a la mano aquí abusiva de Max Brod?

Nietszche explica la elección del personaje de Zaratustra, quien procede de una tradición ajena a la occidental, diciendo que quien primero se equivoca ha de ser quien primero corrija el error. Zaratustra es el sabio lejano que buscó una justificación moral intrínseca en el universo antes que nadie; es quien supuso el bien y el mal como categorías estables escritas por la ley divina; por ello, ha de ser el primero en regresar al mundo con la evidencia de que no hay tal. Algo así podemos ver en el personaje de K.: sus afanes por ingresar al castillo lo colocan en la posición (que, como lectores, atestiguamos desde una tercera persona claramente focalizada sobre él) desde la cual se evidencian todas las contradicciones emanadas de la autoridad que rige el pretendido castillo ${ }^{23}$. Lejos de avanzar en su comprensión o en su descubrimiento de una coherencia escondida del castillo, K. se va 
internando en la evidencia de que algo así no se da: está ya bastante avanzado el texto cuando a duras penas escucha el discurso de Bürgel sobre la complejidad del castillo, que se describe en auténtico tono de pesadilla ${ }^{24}$ (véase Kafka, 1981, pp 375 ss.). Ante su cháchara interminable, que $K$. oye en el entresueño, no se saca en claro sino una cosa: hay que despertarse de ese feo delirio. ¿Cómo podría pensarse que Kafka sugiere, en serio, que una organización como la allí descrita, una organización que da lugar a ese discurso de un secretario como Bürgel, deba tomarse como la obra de un Dios mínimamente cuerdo? K. es capaz de resistir mucho, pero todo tiene un límite y ciertamente su paciencia debe de estar por agotarse, ya que le toca ir más lejos que a nadie, al igual que al Zaratustra nietzscheano. Pero es hasta este punto, hasta ese límite, que el texto se permite avanzar. Más allá no se lo escribe, ¿pero no es para que los lectores demos el paso final, tan insistentemente (aunque no de forma clara, paradoja muy propia del arte kafkiano) insinuado?

En uno de sus aforismos, dice Kafka lo siguiente: "Dos pecados capitales, de los cuales se derivan todos los demás, determinan la vida de los seres humanos: la impaciencia y la indolencia. Fueron expulsados del paraíso a causa de la impaciencia, no regresan debido a la indolencia. Pero quizá sólo hay un pecado capital: la impaciencia. Fueron expulsados a causa de la impaciencia; no regresan debido a la impaciencia." (Kafka, s.f., p. 4) Uno podría leer este aforismo relacionándolo con El castillo de la siguiente manera: los seres humanos, en el exilio de la aldea a que han sido condenados por su primera intención impaciente de ingresar en el castillo ${ }^{25}$, ahora no regresan por indolentes (adjetivo que bien describiría a la gran mayoría de habitantes, como aquí se ha planteado). Pero luego el aforismo corrige: es la impaciencia la que causa la imposibilidad del regreso. Se podría acusar a K. de ser el mayor impaciente; en cierto modo, su actitud es de persecución de las autoridades del castillo, en lugar de espera. Siempre está corriendo K. de un lado a otro: no cuesta pensar que se arroja sobre Frieda no por incontinencia erótica sino por incapacidad de esperar a que Klamm se ocupe de su caso y deseo de llamar su atención quitándole a Frieda. Pero entonces, ¿son los habitantes de la aldea, esos indolentes, quienes se comportan ejemplarmente? El aforismo, al menos como instrumento para la interpretación de El castillo, nos resulta contradictorio: si no se regresa por indolencia, es K. (el impaciente) quien lleva las de ganar; si no se regresa por impaciencia, son los aldeanos (los indolentes) quienes llevan las de ganar. Lo que este aforismo implica es que, en un mundo concebido desde el Génesis, los seres humanos viven esta contradicción irresoluble: si son pacientes pierden por indolencia; si son impacientes pierden por impaciencia. ¿Hasta dónde hay que soportar entonces el atenerse a una concepción de mundo nacida en Génesis? Y si el aforismo "corregido" es el que vale, como se podría pensar, ¿por qué sigue allí la primera versión? Kafka bien podría haber tachado la alusión inicial a la indolencia (recordemos que las tachaduras son frecuentes en estos originales, lo que no nos ha impedido leerlos casi todos: Kafka nunca fue bueno para deshacerse de lo escrito, como lo pudo atestiguar Brod). No lo hace porque sabe que así se subraya el hecho (constante en sus novelas y cuentos, por cierto) de que, desde la concepción teológica judaica de la existencia humana, esta es un callejón sin salida, similar a una pesadilla interminable, y cuyo fin se posterga cruelmente. Seguir viviendo atrapado en ella es antes que otra cosa una tortura; si hay castillo (vale decir, si hay verdad en el Génesis), este implica la perdición humana. Lo que, finalmente, ¿no convierte a la inexistencia del castillo en un horizonte preferible?

Las conclusiones de este ensayo no insistirán, al modo kafkiano, en postergar una conclusión. Para los lectores, no es ningún secreto que la postergación (que aparenta, sin verdad, ser infinita ${ }^{26}$ ) es la más cansina y la más constante de las actividades kafkianas. En mi opinión, ella reviste un doble propósito, que ya he expuesto y ahora resumo. En primer lugar, nos planta frente a la necesidad de reaccionar ante un mundo pesadillesco basado en una relación con una divinidad remota, oscura y confusa, que no alcanzamos a comprender, ni aquí y 
ahora ni tampoco más tarde, en una hipotética vida futura (pues se trata de que el imaginario castillo es y será siempre caótico, acaso la más temible de las demostraciones kafkianas). En segundo lugar, nos permite mirar en el espejo de nuestras constantes y necesarias búsquedas de una trascendencia, cuyo fracaso no podemos evitar asumir, una y otra vez. Si nuestro deseo es ser agrimensores y el castillo solo nos lo permitiría, hemos de volver a buscar el camino hacia él, aunque no existan ni camino ni castillo.

Estos dos propósitos pueden cambiar de lugar, y ser uno más importante que el otro, según nuestra condición y nuestro estado de ánimo. En ocasiones perseveraremos en la pesadilla de la búsqueda de una trascendencia imposible, persuadidos de que sólo así lograremos el propósito de ser quienes somos, sólo así nos aseguraremos una identidad que no sea mero polvo en el viento. En otras ocasiones, pensaremos en despertar de la pesadilla, y aunque nos perdamos a nosotros mismos (ya no seremos jamás agrimensores, y vivimos persuadidos de poder ser eso únicamente ${ }^{27}$ ), habremos roto con un turbio castillo inexistente.

\section{Notas}

1. Uso la traducción de J.A. Moyano Moradillo.

2. Idea que se puede ver originalmente sugerida, como se verá más adelante, por Marthe Robert.

3. La solicitud de K. de una entrevista con Klamm se calificó así por parte de la mesonera, en cuya boca no menguaron las explicaciones: véase Kafka, 1981, pp.96 ss.

4. Los aforismos kafkianos son apenas unas cuantas notas que Kafka jamás preparó para su publicación. No se sabe cuánta solidaridad tuvo Kafka hacia los pensamientos allí expresados, de manera que no pienso que deba tomárselos como manifiestos ciento por ciento genuinos de su forma de ver la realidad. (Ni siquiera creo que haya que tomar así su diario: ¿acaso la gente no se miente a sí misma?) Algunos aforismos se conocen porque se descifró lo que Kafka había tachado. Todo esto puede ayudarnos a comprender su inteligibilidad limitada en ocasiones; de cualquier manera, se trata tan sólo de un caso extremo en la misma dirección que estamos acostumbrados a transitar con este autor: casi todos sus textos fueron rescatados sin que él mediase en la publicación. Anoto que Harold Bloom (1995) piensa que los aforismos son la culminación de la obra literaria kafkiana, lo cual es una exageración muy propia del estilo de este crítico, pero demuestra que en Kafka no hay textos deleznables.

5. Cuentan que cuando atravesaba a nado el canal de la Mancha, y restándole apenas cien metros para llegar, cierto nadador dijo estar muy cansado, e inició el nado en reversa. K. no quiere ser ese nadador, aunque los cien metros que le faltan sean de severa turbulencia.

6. Traducción de Jorge Luis Borges.

7. Otro lector insigne, Thomas Mann, va en el mismo camino.

8. Pero esto no tiene nada de particular; nada más se agotan en sus connotaciones los textos pobres.

9. Recuérdese la diferencia introducida por Umberto Eco entre cooperación y violencia ante los textos literarios. Véase Lector in Fabula.

10. Pese a todo lo cual, hay quien toma el adjetivo "kafkiano" en un sentido humorístico, casi diré que "light": como si se creyera que lo burocrático es molesto, pero no trágico. Algo así como la plaga de mosquitos que enturbia el día en la playa.

11. Véase Isaacson 2005, p. 78.

12. Lamento si esto suena demasiado a derrotismo social y político. Espero que se le asocie más bien con un realismo descarnado pero saludable. Más vale saber dónde vivimos: solo incluyo una pincelada de tal complejidad, no de mi pluma sino de la de Vargas. Veamos el inicio del apartado titulado "Caracterización de los actores de la globalización", de otro libro interesantísimo, El candado y la llave: "Para diferenciar actores hegemónicos y actores subalternos, fundamentalmente recurro a un criterio económico, en relación con una variable fundamental: el grado de control sobre los medios de producción decisivos $\mathrm{y}$, en consecuencia, sobre la producción y la distribución de esta última. / Cuando digo medios de producción decisivos me estoy refiriendo a las industrias y las actividades 
líderes de la economía y, al mismo tiempo, al control de las grandes corporaciones y empresas donde cobran materialidad las grandes acumulaciones de capital, así como el control de los flujos decisivos de capital, inversión y comercio y los procesos de desarrollos científico y tecnológico, en especial los que se sitúan en posición puntera. / Cuando digo control de los medios de producción decisivos, incluyo el control directo sobre estos -ejercido por las burguesías transnacionalizadas que cobran corporeidad principalmente en las gigantescas corporaciones transnacionales o en los agentes u operadores globales de capital financiero-pero también las formas indirectas por medio de las cuales se tiene acceso a ese control del capital y la producción. En este último caso, hago referencia a los estamentos políticos dominantes, como, asimismo, los actores mediáticos más poderosos, en cuyas manos se deposita un poder gigantesco destinado a la reproducción ideológica del sistema. A medio camino, entre aquellos actores políticos y estos actores mediáticos, aparecen distintos actores de formación de ideología (principalmente los llamados think tanks, pero también, según el caso, las instituciones religiosas),..." (Vargas, 2010, pp. 11-12)

13. En "Los procesos invisibles" comenté que en Kafka la pesadilla no es un estado que produzca un terror absoluto ni una necesidad de escape. De hecho, dije que Kafka se sabía personalmente incapaz de sobrepasar la pesadilla y que sólo se pensaba artista en tanto soñador productor de malos sueños. En este tercer ensayo que dedico a Kafka, como se irá viendo paulatinamente, me atrevo - no obstante lo anteriormente dicho- $\mathrm{a}$ ir más allá de las preferencias personales de Kafka para hablar de lo que el texto kafkiano puede llegar a significar en relación con la condición humana pesadillesca y su posible, aunque trágica, superación.

14. Wittgenstein (1973, pp. 199-201)

15. No se vaya a olvidar que yo no estoy amenazando pecadores, sino tan sólo sugiriendo (sin tener en él la fe más mínima) un destino terrible para todos los seres humanos.

16. En "Los procesos invisibles" me interesé en este punto; allí además tomé en cuenta el caso clásico de Iván Karamázov.

17. Perfectamente, aunque la paradoja sea aquí que la perfección implica el no acabamiento de la búsqueda, la interminable postergación del encuentro.

18. Esto es independiente, insisto, del hecho de que Franz Kafka haya sido una persona capaz de dar este paso. Todo hace suponer que no: sin entrar en especulaciones psicológicas, hay que recordar, como he sugerido en los dos ensayos anteriores, que su amor por la pesadilla era también amor por su arte.

19. A los cuales está claro que inducen las autoridades terrenales que se proclaman voceras del castillo.

20. Qué extraño es esto. La grosería, que suele ser de lo más explícita (incluso, se la comete por no saber aludir indirectamente a los asuntos engorrosos) más bien está dada, en la carta misteriosa, en términos que dificultan la comprensión del sentido. No puedo sino relacionar esta carta con ciertos textos amenazantes producidos por las religiones, de los que finalmente no se puede extraer sino un sentido de conjunto sumamente agresivo, pero cuyas partes solo parecen provocadas por el delirio incoherente. Algo como El Apocalipsis. Claro está que estos son supuestos, porque la carta no se reproduce nunca.

21. Pero ella tampoco es como K., pues lo que más parece anhelar es huir del lugar. Cuando K. no consiente en ello, vuelve Frieda a ser una oveja más en el redil de los aldeanos. Es posible, sin embargo, que el personaje sea más complejo, porque representa al único individuo que, estando más cerca del castillo, trata, al menos en algún momento, de alejarse de este: deja a Klamm y se va con K. ¿ Su justificación sería el amor a K o el hartazgo con la situación precaria a la que Klamm la somete? No queda demasiado claro: este es uno de los precios que hay que pagar por el hecho de que la narraciónsiga tan de cerca, y tan exclusivamente, los pasos de K. Lo cierto es que sobre los demás personajes sólo alcanzamos a saber lo que K. vislumbra.

22. Por cierto, desde mi punto de vista, tampoco lo hace Joseph K. en El proceso, según lo expuse en los ensayos ya citados.

23. Y esta es una ventaja muy valiosa de lo que comenté al final de la nota 21 .

24. La cual, veremos enseguida, es dudosa. Una cosa es resistencia y otra es paciencia. 
25. Claro que de este episodio no tenemos noticia. La historia conocida comienza sin memoria del Génesis; la fe exige aceptar la verdad de la leyenda.

26. No puede serlo porque la vida humana no lo es. En algún momento, K. llegaría a desgastarse y moriría, muy seguramente sin entrar en el castillo.

27. Kafka sólo quiere ser artista, y sólo puede ser artista de la pesadilla. Difícilmente él se atrevería a darle prioridad a lo segundo, si bien su obra llega a sugerirlo con mucha fuerza.

\section{Bibliografía}

Bajtín, Mijaíl. 1988. Problemas de la poética de Dostoievski. (Traducción de Tatiana Bubnova) Fondo de Cultura Económica, México.

Barthes, Roland. 1987. S/Z. Traducción de Nicolás Rosa. Siglo XXI: México, D.F.

Blanchot, Maurice, 1981. De Kafka a Kafka. Gallimard: Paris.

Bloom, Harold. 1995. El canon literario. Traducción de Damián Alou. Anagrama: Barcelona.

Camus, Albert (s.f.) El hombre rebelde. Alfa Omega: Santo Domingo.

Camus, Albert. 1983. El mito de Sísifo. Alianza, Madrid.

Cervantes, Miguel de. 1999. El Ingenioso Hidalgo don Quijote de la Mancha. Edición de Martín de Riquer. Planeta: Barcelona.

Deleuze, Gilles y Félix Guattari. 1978. Kafka. Por una literatura menor. Traducción de Jorge Aguilar Mora. Ediciones Era: México, D.F.
Dodd, W.J. 1992. Kafka and Dostoievsky. The Shaping of Influence. St. Martin's Press: London.

Dostoievski, Fédor. 1964. Crimen y castigo. Traducción de José Fernández. Editorial Juventud: Barcelona.

Dostoievski, Fédor. 1983. Los hermanos Karamázov. Traducción de Augusto Vidal. Bruguera: Barcelona.

Eco, Umberto. 1995. Semiótica y filosofía del lenguaje. Lumen: Barcelona.

Eco, Umberto. 1999. Arte y belleza en la estética medieval. Lumen: Barcelona.

Eco, Umberto. 1975. Obra Abierta. Lumen: Barcelona.

Eco, Umberto. 1981. Lector in Fabula. Lumen: Barcelona.

Gutiérrez, Claudio. 2006. Ensayos sobre un nuevo humanismo. Editorial EUNED: San José.

Herra, Rafael Ángel. 2007. Autoengaño. Palabras para todos y sobre cada cual. EUCR: San José.

Hitchens, Christopher. 2008. Dios no es bueno. Alegato contra la religión. Debate: México, D.F.

Isaacson, José. 2005. La realidad metafísica de Franz Kafka. Corregidor: Buenos Aires.

Kafka, Franz. 1984. Cartas a Felice. Traducción de J.R. Wilcock. Alianza Editorial: Madrid.

Kafka, Franz. 1992. Obras selectas. Edición de Antonio Massone. Traducción de D.J. Vogelmann. Andrés Bello: Buenos Aires. 
Kafka Franz. 1970. La metamorfosis. Traducción de Jorge Luis Borges. Losada: Buenos Aires.

Kafka, Franz. 2001. La condena. Traducción de J.R. Wilcock. Alianza Editorial: Madrid.

Kafka, Franz. 1974. Carta al padre. Traducción de Feliu Formosa. Lumen: Barcelona.

Kafka, Franz. 1985. El buitre. Selección y prólogo de Jorge Luis Borges. Emecé: Madrid.

Kafka, Franz. 1981. El castillo. Traducción de J. A. Moyano Moradillo. EDAF: Madrid.

Kafka, Franz. 1982. América. Traducción de D.J. Vogelmann. Alianza Editorial: Madrid.

Kafka, Franz (s.f.). Aforismos. Traducción de Librodot.com en http: //www.bsolot. info/ wp-content/uploads/2011/02/ Kafka_Franz-Aforismos_visiones_y_ sue $\%$ C 31 os.pdf, consultado el 1 de abril de 2011.

Lombardo Radice, Lucio. 1977. El acusado Kafka. Icaria: Barcelona.

Murray, Nicholas. 2006. Kafka. Literatura y pasión. Traducción de Silvia Kot. El Ateneo: Buenos Aires.
Nietzsche, Friedrich. 1999. Así habló Zaratustra. Traducción de Javier Carretero Moreno. Edimat: Madrid.

Robert, Marthe. 1969. Kafka. Traducción de Carlos A. Fayard. Paidós: Barcelona.

Sánchez Trujillo, Guillermo. 2004. Crimen y castigo de Franz Kafka. Libros en red: United Kingdom.

Todorov, Tzvetan. 1991. Crítica de la crítica. Paidós, Barcelona.

Vargas, Luis Paulino. 2008. El verdadero rostro de la globalización. Editorial EUNED: San José.

Vargas, Luis Paulino. 2010. El candado y la llave. Editorial EUNED: San José.

Wagenbach, Klaus. 1969. La juventud de Franz Kafka. Traducción de Roberto J. Vernengo. Monte Avila Editores: Caracas.

Wittgenstein. 1973. Tractatus lógicophilosophicus. Traducción de Enrique Tierno Galván. Introducción de Bertrand Russell. Alianza: Madrid.

\section{(9) $\odot \otimes \Theta$}

Este obra está bajo una licencia de Creative Commons Reconocimiento-NoComercial-SinObraDerivada 4.0 Internacional. 